\title{
High-resolution quantitative 3D T2 mapping allows quantification of changes in edema after myocardial infarction
}

Haiyan Ding ${ }^{1,2^{*}}$, Michael Schär ${ }^{5,4}$, MM Zviman ${ }^{3}$, Henry R Halperin ${ }^{3}$, Roy Beinart ${ }^{3}$, Daniel A Herzka ${ }^{2}$

From 16th Annual SCMR Scientific Sessions

San Francisco, CA, USA. 31 January - 3 February 2013

\section{Background}

T2 values are related to the tissue water content, providing useful diagnostic information in cardiac diseases, especially in acute states such as myocardial infarction (MI). Visualization of edema, its regional distribution, and extent in acute and chronic heart disease may be useful as a diagnostic tool and help in guiding treatment in the patients with heart disease. Recently, edema detection (T2 elevation) using quantitative T2 maps has been shown more robust than qualitative clinical $\mathrm{T} 2 \mathrm{~W}$ imaging.

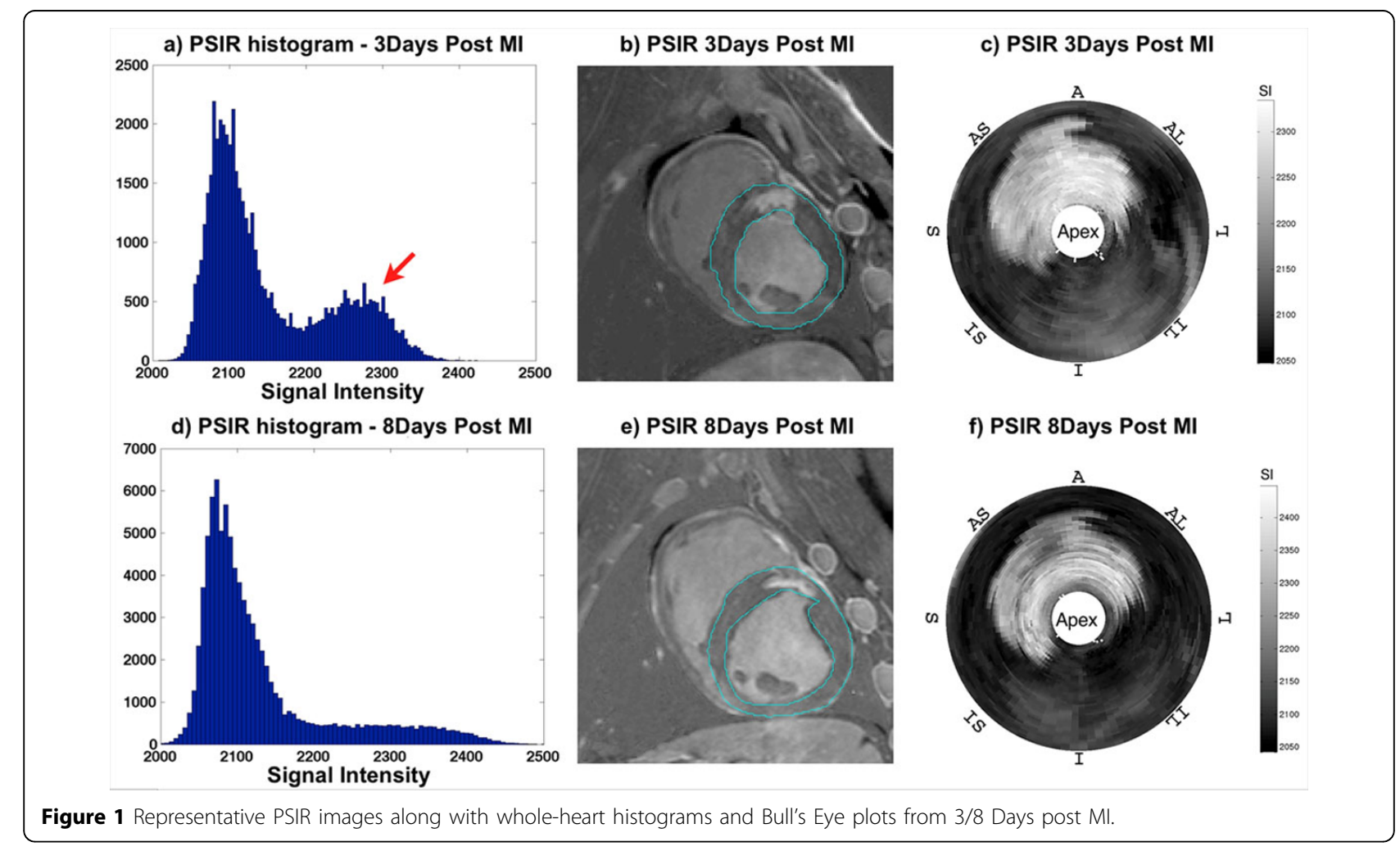

'Biomedical Engineering, Tsinghua University, Beijing, China

Full list of author information is available at the end of the article

(c) 2013 Ding et al; licensee BioMed Central Ltd. This is an Open Access article distributed under the terms of the Creative Commons Attribution License (http://creativecommons.org/licenses/by/2.0), which permits unrestricted use, distribution, and reproduction in any medium, provided the original work is properly cited. 


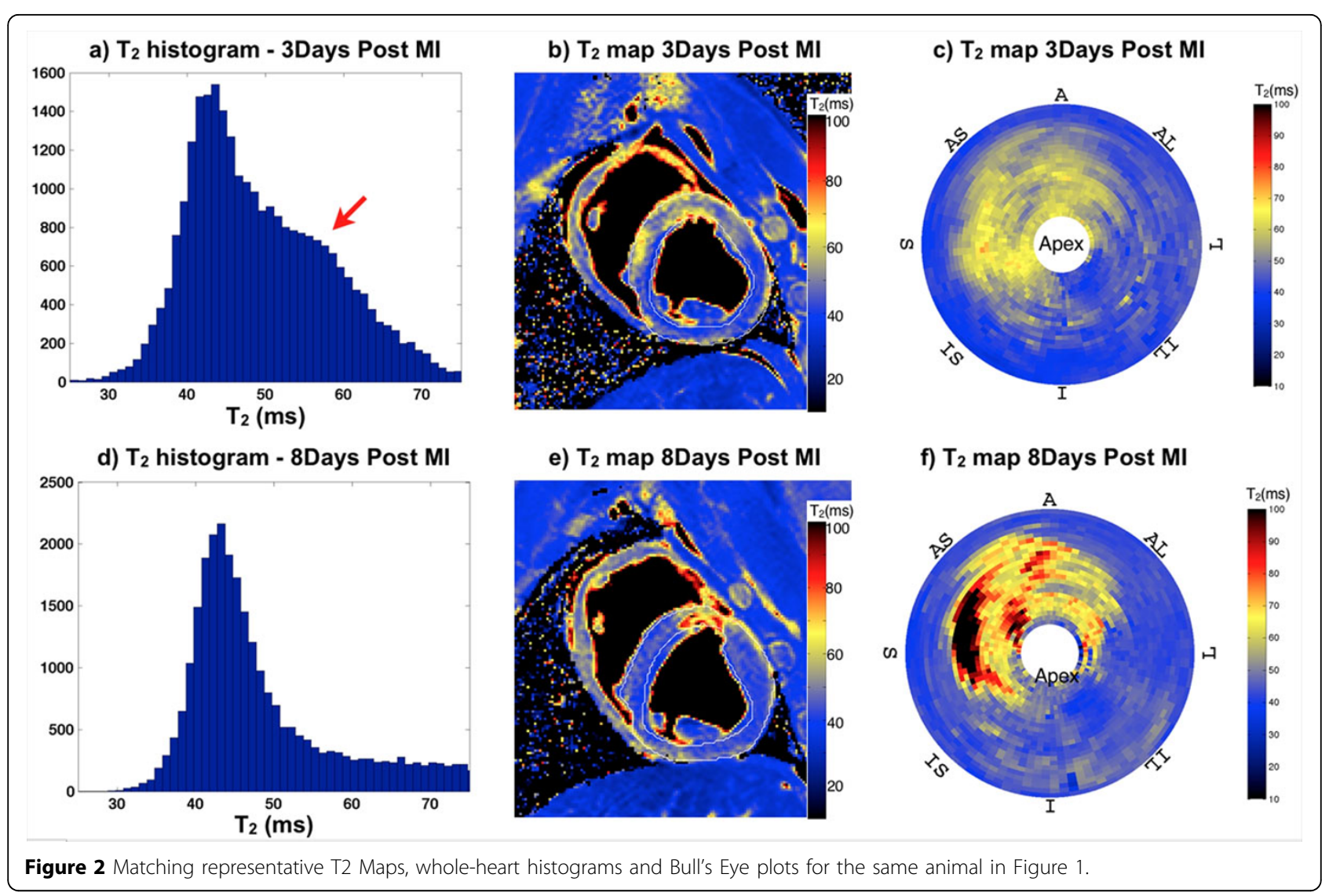

Hypothesis: Whole heart coverage T2 mapping makes the global edema distribution available for quantitative myocardial edema assessment in the context of subacute MI.

\section{Methods}

Under IACUC-approved protocol, MI was induced in swine $(\mathrm{N}=4)$ by $120 \mathrm{~min}$ occlusion of the mid LAD. Imaging was carried out 2 to 9 days post MI using an Achieva 3T TX system (Philips Healthcare, Best, Netherlands). Normal animals $(\mathrm{N}=4)$ were imaged for reference T2 values. T2-mapping of the ventricles was carried using previously presented free-breathing 3D sequence. Postcontrast 3D Late Gadolinium enhancement with phase sensitive inversion recovery (PSIR) images were acquired $\sim 30 \mathrm{~min}$ post infusion of $0.2 \mathrm{mmol} / \mathrm{kg}$ of Magnevist. Both sequences were acquired in high-resolution $(\sim 1.0 \times 1.25 \times 3$ $\mathrm{mm} 3$ for PSIR, $1.25 \times 1.25 \times 5 \mathrm{~mm} 3$ for T2 Maps) during free-breathing using independent respiratory navigator gating.

3D T2 maps were calculated per voxel using linear regression of the log of the signal. Pixels with poor fits (corr. coeff. $\mathrm{R} 2<0.9$ ) were rejected. The left ventricle (LV) was manually segmented, excluding papillary muscle and epicardial/endocardial boundaries.

\section{Results}

MI with edema was observed in all animals; 3 animals displayed evidence of hemorrhage/clotting injuries as evidenced by microvascular obstruction and concomitantly reduced T2. Figs. 1 and 2, show representative short-axis post MI PSIR and T2 map images, respectively, along with whole LV volume histograms and Bull's Eye plots. Data demonstrate the dissipation of edema (increased T2) over time (red arrows). PSIR viability volumes display the extent of infarct, with infarct size decreasing from 3 days post MI to 8 days. T2 and edema increase in the same time span.

\section{Conclusions}

The high resolution quantitative T2 maps enables monitoring of physiological changes over time, providing an objective assessment on the evolution of edema post MI.

\section{Funding}

This work was funded in part by AHA-11SDG5280025.

Author details

${ }^{1}$ Biomedical Engineering, Tsinghua University, Beijing, China. ${ }^{2}$ Biomedical Engineering, Johns Hopkins University School of Medicine, Baltimore, MD, USA. ${ }^{3}$ Medicine, Cardiology, Johns Hopkins University School of Medicine, Baltimore, MD, USA. ${ }^{4}$ Russell H. Morgan Department of Radiology and 
Radiological Science, Johns Hopkins University School of Medicine, Baltimore, MD, USA. ${ }^{5}$ Philips Healthcare, Cleveland, OH, USA.

Published: 30 January 2013

doi:10.1186/1532-429X-15-S1-P181

Cite this article as: Ding et al:: High-resolution quantitative 3D T2

mapping allows quantification of changes in edema after myocardial infarction. Journal of Cardiovascular Magnetic Resonance 2013 15(Suppl 1): P181.

Submit your next manuscript to BioMed Central and take full advantage of:

- Convenient online submission

- Thorough peer review

- No space constraints or color figure charges

- Immediate publication on acceptance

- Inclusion in PubMed, CAS, Scopus and Google Scholar

- Research which is freely available for redistribution

Submit your manuscript at www.biomedcentral.com/submit
() Biomed Central 